\title{
Research Paper: \\ Review, Documentation, Assessment of Treatment, and Harm Reduction Programs of Substance Use Disorder in Iranian Prisons
}

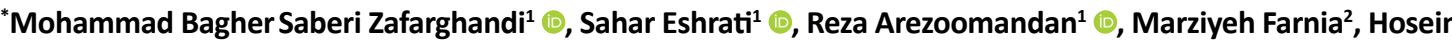

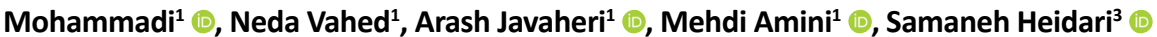

1. Department of Addiction, School of Behavioral Sciences and Mental Health (Tehran Institute of Psychiatry), Iran University of Medical Sciences, Tehran, Iran.
2. Education and Research Office of Iranian Prisons Organization, Tehran, Iran.

3. Trauma and Injury Research Center, Iran University of Medical Sciences, Tehran, Iran.

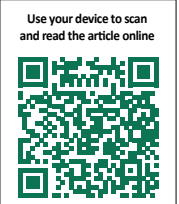

Citation Saberi Zafarghandi MB, Eshrati S, Arezoomandan R, Farnia M, Mohammadi H, Vahed N, et al. [Review, Documentation, Assessment of Treatment, and Harm Reduction Programs of Substance Use Disorder in Iranian Prisons (Persian)]. Iranian Journal of Psychiatry and Clinical Psychology. 2021; 27(1):48-63. http://dx.doi.org/10.32598/ijpcp.27.1.3324.1

doi hittp://dx.doi.org/10.32598/ijpcp.27.1.3324.1

Received: 31 Jan 2020 Accepted: $27 \operatorname{Sep} 2020$ Available Online: 01 Apr 2021

Key words:

Harm reduction, Addiction, Prison, Illegal drugs

\section{A B STRACT}

Objectives This study aims to assess the implementation of drug-related harm reduction programs in Iranian prisons and suggest solutions for their improvement.

Methods This study was conducted in three steps. First, library method was used for collecting data from the central library of Iran's Prisons, Security and Corrective Measures Organization. In the second step, performance indicators were extracted based on the results of first step and two researcher-made checklists were designed. Finally, a field visit and a semi-structured interview with the authorities involved in the treatment and harm reduction services were carried out.

Results In most of prisons, drug-related harm reduction programs were underway. Despite a lack of human resources and budget at the beginning, the quality of measures was gradually increased and the attitude of authorities was improved. Methadone Maintenance Treatment and Triangular Clinics were the most common harm reduction programs, in addition to HIV and tuberculosis screening programs in collaboration with medical sciences universities. The program continued despite the change of officials. Conclusion Harm reduction programs are able to reduce infection diseases, self-harm and violent behaviors in prisons of Iran. Cultural programs along with other harm reduction programs, briefings and seeking support from the authorities can greatly help with continuation of the programs in prisons. By eliminating the shortage of manpower and redefining the security areas for ordinary prisoners, it will be possible to make better use of the facilities of universities and research centers.

\section{Extended Abstract}

\section{Introduction}

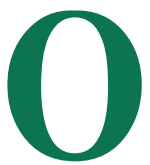

ne of the major problems in prisons is the increased drug use. It is estimated that the number of People Who Use Drugs (PWUDs) in prisons is $70 \%$. The risk of $\mathrm{HIV}$ transmission in prisons is also high since a significant percentage of PWUDs inject drugs. On the other hand, the frequency of high-risk behaviors in a prison can increase the likelihood of the spread of related diseases in society. Therefore, development of policies and treatment programs for reduction of drug-related harm in prisons are of great importance. In this regard, the health department of Iran's Prisons, Security and Corrective Measures Organization has implemented programs since the late 1991 to improve the health of prisoners and reduce the risks for public

\section{* Corresponding Author:}

Mohammad Bagher Saberi Zafarghandi, PhD.

Address: Department of Addiction, School of Behavioral Sciences and Mental Health (Tehran Institute of Psychiatry), Iran University of Medical Sciences, Tehran, Iran.

Tel: +98 (21) 63471301

E-mail: saberi.mb@iums.ac.ir 
health. One of the concerns of the relevant authorities is the documentation of harm reduction measures and their modification in accordance with the conditions of the prisons. The present study aims to assess the implementation of drug-related harm reduction programs in prisons of Iran and suggest solutions for their improvement.

\section{Methods}

This is a descriptive cross-sectional study conducted in three steps. First, library method was used to collect information from the documents available in the library of Iran's Prisons, Security and Corrective Measures Organization. In the second step, performance indicators were extracted and two researcher-made checklists were designed. The face and content validity of the checklists were evaluated based on the opinions of a panel of experts. The third step included a field visit through a semi-structured interview with service providers, service recipients, and prison authorities involved in the implementation of treatment programs and measures for harm reduction.

\section{Results}

The harm reduction programs were implemented since 2001 with the Methadone Maintenance Treatment (MMT) program conducted as a pilot in Ghezel Hesar Prison. To date, the treatment and harm reduction programs have been implemented in the most Iranian prisons with two major programs including MMT and triangular clinic. Table 1 summarizes the performance indicators of harm reduction programs in provincial prisons of Iran.

As can be seen in Table 1, the coverage rate of programs especially MMT in all prisons was almost $100 \%$. Half of the provinces had no waiting list for treatment, $27 \%$ had a considerable number of waiting lists and $23 \%$ had low to moderate number of waiting lists. There was shortages of space, staff and budget in all prisons, which was one of the serious barriers to providing services according to the standards of the Ministry of Health. Most of prisons in provinces provided post-release services except in three provinces of Semnan, Kurdistan and Qazvin. Inadequate post-release services were considered as a factor in returning to prison. There was no monitoring and evaluation of the programs in any provinces. One of its reasons was the impossibility of cooperating with other organizations, such as medical sciences universities, research centers, and researchers outside of the prison. Based on field evidence and previous experience, prison officials acknowledged that harm reduction and treatment services had reduced mortality (especially in the quarantine unit), overuse of drugs, self-harm, suicide attempts, and violence.

\section{Discussion and Conclusion}

The harm reduction programs in prisons of Iran included MMT, diagnosis and treatment of HIV, hepatitis and sexually transmitted diseases as well as psychological interventions and NA meetings. Filed study and interviews revealed the effectiveness of these programs and, despite the budget and staff shortages, they had not been stopped. The implementation of some programs such as vocational training and recreational programs, although were not a part of harm reduction programs, helped reduce harms in prisons. Separate monitoring and evaluation of each program is required. One of the barriers was difficulty in cooperating with organizations such as medical sciences universities. Establishing regular meetings and persuading provincial officials such as judges, and providing advocacy support to the programs are the most important strategies for the continuation of the programs. The main challenges facing these programs were weakness in providing post-release services, insufficient staff and budget, inability to carry out the programs in accordance with the standard protocols, and difficulty in persuading some authorities and judges in implementing these programs. Increasing post-release services, staff and budget, and organizing training courses for the personnel of prisons are recommended.

\section{Ethical Considerations}

\section{Compliance with ethical guidelines}

All ethical principles are considered in this article. The participants were informed about the purpose of the research and its implementation stages. They were also assured about the confidentiality of their information and were free to leave the study whenever they wished, and if desired, the research results would be available to them.

\section{Funding}

This study was supported by the Office of Education and Research of Prisons, Security and Corrective Measures Organization.

\section{Authors contributions}

Data collection: Mohammad Bagher Saberi Zafarghandi, Reza Arezoomandan, Arash Javaheri, Neda Vahed, Hosein Mohammadi, \& Samaneh Heidari; Conducting interview: Mohammad Bagher Saberi Zafarghandi, Reza Arezoomandan, Hosein Mohammadi, \& Samaneh Heidari; Transcription of interviews: Neda Vahed, Samaneh Heidari, and Sahar Eshrati; Study design: Mohammad Bagher Saberi 
Table 1. Performance indicators of harm reduction programs in Iranian prisons

\begin{tabular}{|c|c|c|c|c|c|c|c|}
\hline Province & $\begin{array}{l}\text { Compliance } \\
\text { with Protocol }\end{array}$ & $\begin{array}{l}\text { Initial Screening } \\
\text { of Prisoners }\end{array}$ & Coverage & Facilities & $\begin{array}{c}\text { Post-release } \\
\text { Services }\end{array}$ & $\begin{array}{l}\text { Monitoring } \\
\text { \& Evaluation }\end{array}$ & $\begin{array}{l}\text { Continuity } \\
\text { of Programs }\end{array}$ \\
\hline Ardebil & V & $\mathrm{V}$ & High & Shortage of staff & $\sqrt{ }$ & $x$ & V \\
\hline Esfahan & V & V & High & $\begin{array}{l}\text { Shortage of staff and } \\
\text { budget }\end{array}$ & $\checkmark$ & $x$ & V \\
\hline Alborz & V & V & High & $\begin{array}{c}\text { Shortage of space and } \\
\text { budget }\end{array}$ & V & $x$ & V \\
\hline Elam & V & V & High & $\begin{array}{l}\text { Shortage of space, } \\
\text { staff, and budget }\end{array}$ & V & $x$ & V \\
\hline Eat Azerbaijan & V & V & High & Shortage of budget & V & $x$ & V \\
\hline West Azerbaijan & V & V & High & $\begin{array}{l}\text { Shortage of space and } \\
\text { budget }\end{array}$ & V & $x$ & V \\
\hline Bushehr & V & V & High & $\begin{array}{l}\text { Shortage of staff and } \\
\text { budget }\end{array}$ & V & $x$ & V \\
\hline Tehran & V & V & Moderate & $\begin{array}{l}\text { Shortage of space, } \\
\text { staff, and budget }\end{array}$ & V & $x$ & V \\
\hline $\begin{array}{l}\text { Chaharmahal } \\
\text { and Bakhtiari }\end{array}$ & V & V & Low & $\begin{array}{l}\text { Shortage of space, } \\
\text { staff, budget }\end{array}$ & V & $x$ & V \\
\hline South Khorasan & V & $\checkmark$ & Low & $\begin{array}{c}\text { Shortage of staff and } \\
\text { budget }\end{array}$ & V & $x$ & V \\
\hline Khorasan Razavi & V & V & High & $\begin{array}{l}\text { Shortage of space, } \\
\text { staff, and budget }\end{array}$ & V & $x$ & V \\
\hline $\begin{array}{c}\text { Khorasan } \\
\text { North }\end{array}$ & $\mathrm{V}$ & V & High & $\begin{array}{c}\text { Shortage of space and } \\
\text { staff }\end{array}$ & V & $x$ & V \\
\hline Khuzestan & V & V & High & Shortage of staff & V & $x$ & V \\
\hline Zanjan & V & V & High & $\begin{array}{c}\text { Shortage of space and } \\
\text { staff }\end{array}$ & V & $x$ & V \\
\hline Semnan & V & V & High & $\begin{array}{c}\text { Shortage of space and } \\
\text { staff }\end{array}$ & $x$ & $x$ & V \\
\hline $\begin{array}{l}\text { Sistan and } \\
\text { Baluchestan }\end{array}$ & V & V & High & $\begin{array}{l}\text { Shortage of staff and } \\
\text { budget }\end{array}$ & V & $x$ & V \\
\hline Fars & V & V & High & Shortage of staff & V & $x$ & V \\
\hline Qazvin & V & V & High & $\begin{array}{c}\text { Shortage of space and } \\
\text { staff }\end{array}$ & $x$ & $x$ & v \\
\hline Qom & V & V & High & Shortage of budget & V & $x$ & $\mathrm{~V}$ \\
\hline Kurdistan & V & V & High & Shortage of budget & $x$ & $x$ & V \\
\hline Kerman & V & V & High & Shortage of budget & V & $\times$ & $\mathrm{V}$ \\
\hline Kermanshah & V & V & Medium & $\begin{array}{c}\text { Shortage of staff and } \\
\text { budget }\end{array}$ & $\sqrt{ }$ & $x$ & v \\
\hline $\begin{array}{l}\text { Kohgiluyeh and } \\
\text { Boyer-Ahmad }\end{array}$ & v & v & $\begin{array}{l}\text { Incom- } \\
\text { plete }\end{array}$ & $\begin{array}{c}\text { Incomplete informa- } \\
\text { tion }\end{array}$ & v & Incomplete & Incomplete \\
\hline Golestan & V & V & Low & $\begin{array}{c}\text { Shortage of space and } \\
\text { staff }\end{array}$ & V & $x$ & $\mathrm{~V}$ \\
\hline
\end{tabular}




\begin{tabular}{|c|c|c|c|c|c|c|c|}
\hline Province & $\begin{array}{l}\text { Compliance } \\
\text { with Protocol }\end{array}$ & $\begin{array}{l}\text { Initial Screening } \\
\text { of Prisoners }\end{array}$ & Coverage & Facilities & $\begin{array}{l}\text { Post-release } \\
\text { Services }\end{array}$ & $\begin{array}{l}\text { Monitoring } \\
\text { \& Evaluation }\end{array}$ & $\begin{array}{l}\text { Continuity } \\
\text { of Programs }\end{array}$ \\
\hline Guilan & $\checkmark$ & $v$ & High & $\begin{array}{l}\text { Shortage of space, } \\
\text { staff, and budget }\end{array}$ & $\checkmark$ & $x$ & $v$ \\
\hline Lorestan & $\checkmark$ & $\checkmark$ & High & $\begin{array}{c}\text { Shortage of space and } \\
\text { budget }\end{array}$ & $\checkmark$ & $x$ & $\checkmark$ \\
\hline Mazandaran & $v$ & $v$ & High & $\begin{array}{c}\text { Shortage of staff and } \\
\text { budget }\end{array}$ & $\checkmark$ & $x$ & $v$ \\
\hline Markazi & $\checkmark$ & $\checkmark$ & High & Shortage of staff & $\checkmark$ & $x$ & $v$ \\
\hline Hormozgan & $v$ & $v$ & High & Shortage of budget & $\checkmark$ & $x$ & $v$ \\
\hline Hamedan & $\checkmark$ & $\checkmark$ & High & $\begin{array}{l}\text { Incomplete informa- } \\
\text { tion }\end{array}$ & $\checkmark$ & $\checkmark$ & $\checkmark$ \\
\hline Yazd & $\checkmark$ & $v$ & High & $\begin{array}{c}\text { Shortage of space and } \\
\text { staff }\end{array}$ & $\checkmark$ & $x$ & $\checkmark$ \\
\hline
\end{tabular}

Zafarghandi, Reza Arezoomandan, Marziyeh Farnia, \& Sahar Eshrati; Final approval: All authors.

\section{Conflicts of interest}

The commissioner of this study was the Prisons, Security and Corrective Measures Organization. The study would not have been possible without the cooperation of the Deputy for Research and the Health Department of the organization. Participation of affiliated members in compiling reports and preparing the article can be an example of conflicts of interest, although they just provided scientific and executive assistance and the final analysis was done without organizational bias.

\section{Acknowledgements}

The authors would like to express their gratitude to Dean and Vice-Chancellor for Education of the School of Behavioral Sciences and Mental Health, members of the Department of Addiction Studies, Iran University of Medical Sciences (Dr. Imran Mohammad Razaghi, Dr. Haddadi, Dr. Sabahi Kermani, Dr. Alavi, Dr. Mortazavi, Dr. Nazem for assistance in collecting data, and Dr. Shabazi and Dr. Jafar Bolhari for participation in the interview), and staffs of the Office of Education and Research of Prisons, Security and Corrective Measures Organization. 
This Page Intentionally Left Blank 
مقاله يخوهشى:

مرور، مستندسازى و يايش برنامههاى درمان و كاهش آسيب اعتياد در زندانهاى ايران

•محمدباقر صابرى زفرقندى' هـ، سحر عشرتى' ه، رضا آرزومندان' هـ، مرضيه فرنيا'، حسين محمدى' هـ، ندا واحد'، آرش جواهرى' هـ،

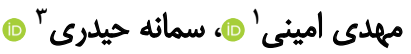

ا. كروه مطالعات اعتياد، دانشكده علوم رفتارى و سلامت روان (انستيثو روانيزشكى تهران)، دانشعاه علوميزشكى ايران، تهران، ايران.

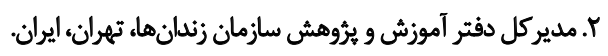

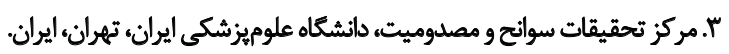

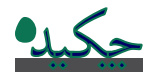

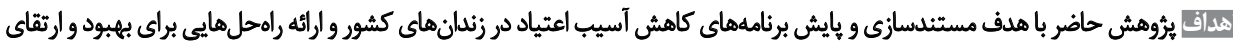

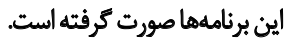

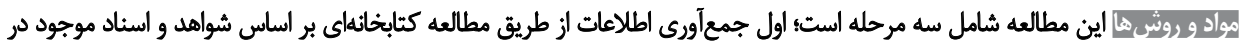

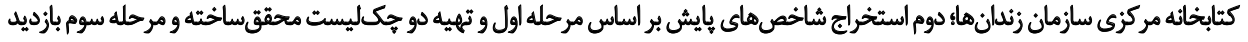

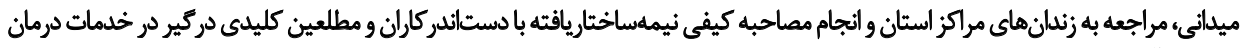
و كاهش آسيب.

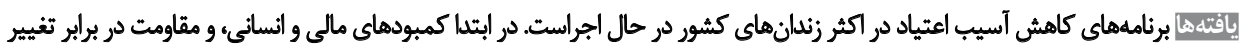

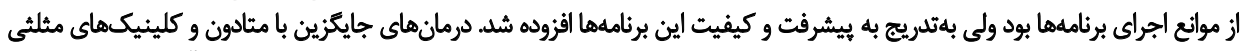

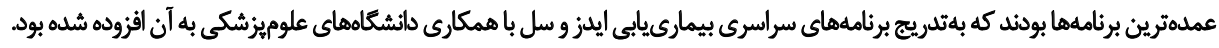

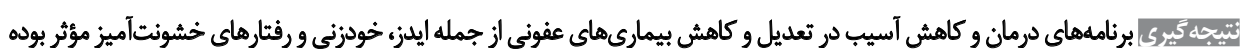

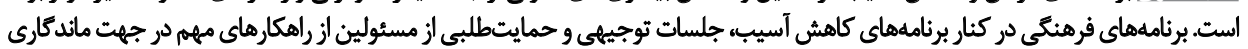

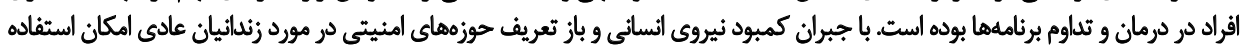

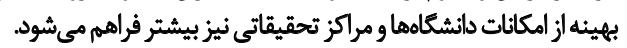

تاريخ دريافت: 11 بهمن

تاريخ بذيرش: 9 مهر 119

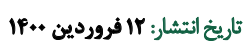

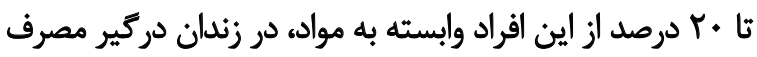

مقدمه

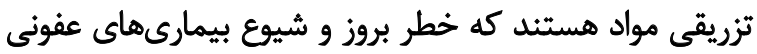

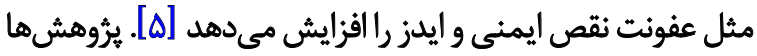

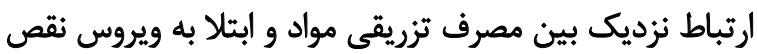

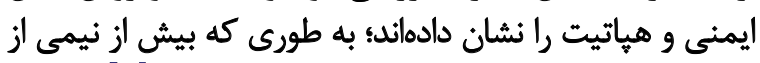

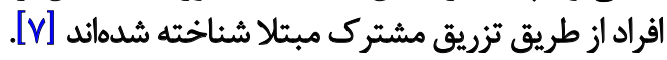

ميزان شيوع اعتياد در زندانها توجهبرانكيز است و بعضى از

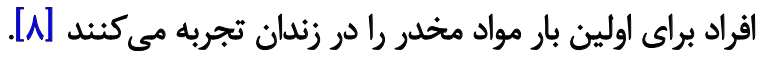

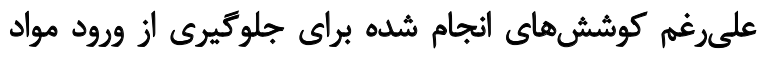

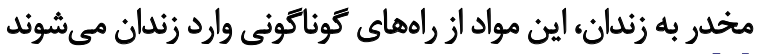

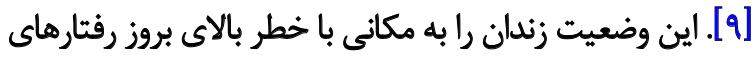

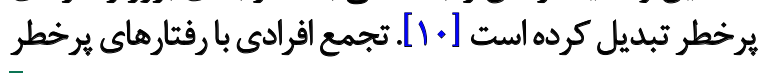

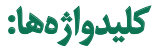

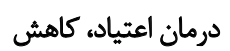

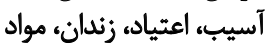

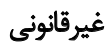

امروزه يكى از مشكلات اساسى زندانها در همه كشور ها مسائل

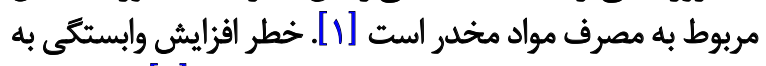

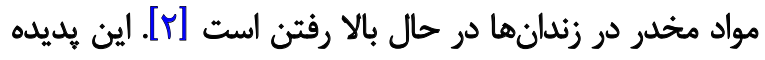

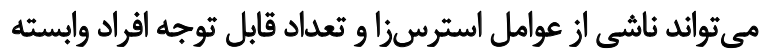

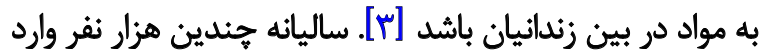

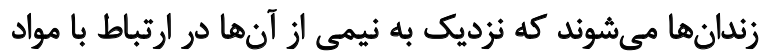

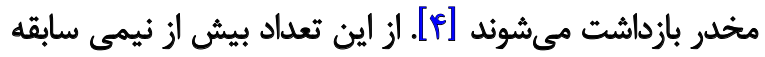

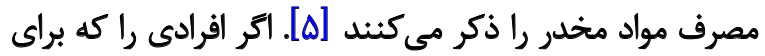

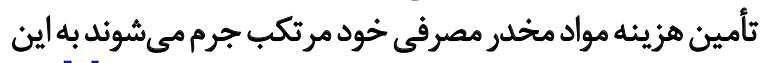

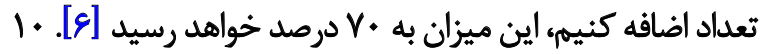

: نويسنده مسئول:

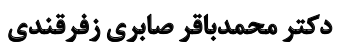

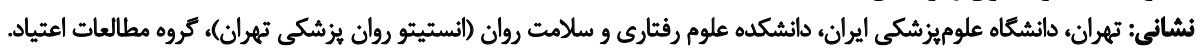
تلفئ: saberi.mb@iums.ac.ir يست الكترونيكي 
محقق ساخته طراحى شد. دو سياهه وارسى بر اساس ارزشيابى دواني

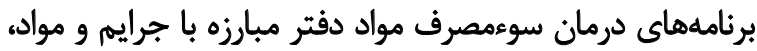

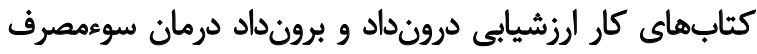

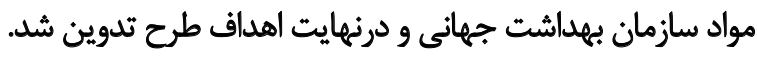

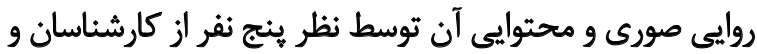

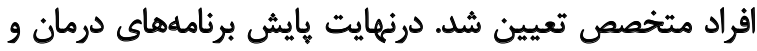

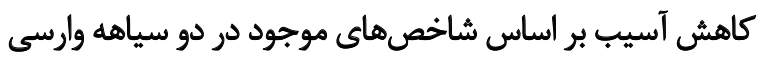

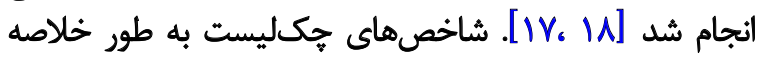

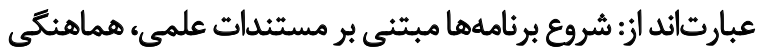

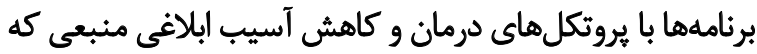

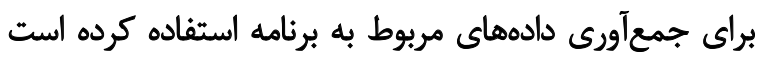

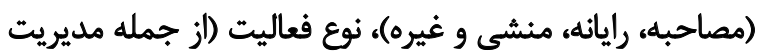

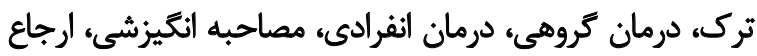

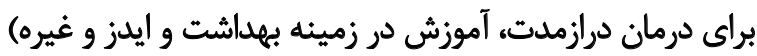

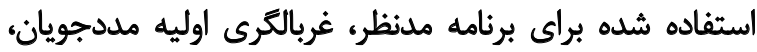

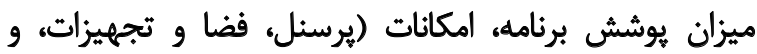

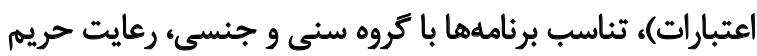

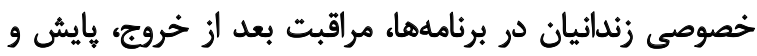

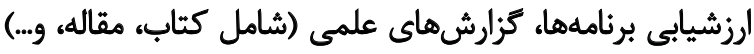

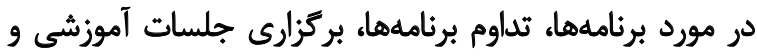

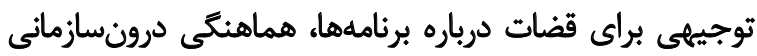

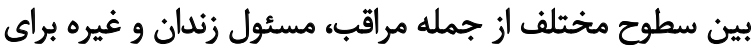

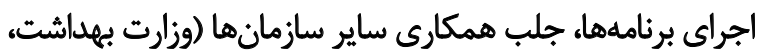

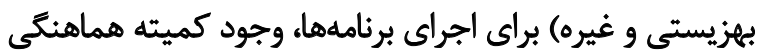

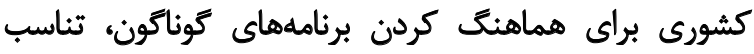

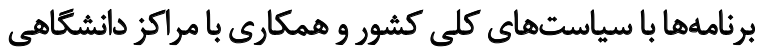
و تحقيقاتى درباره برنامه مد نظر.

مرحله سوم مطالعه به صورت ميداني از طريق مراجئ تراجيه

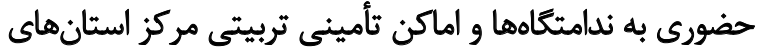

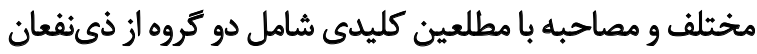

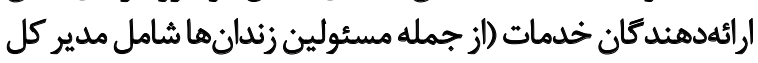

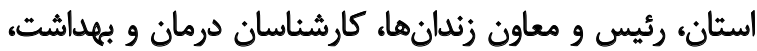

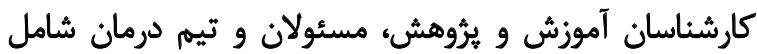

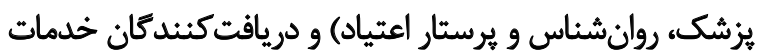

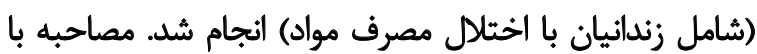

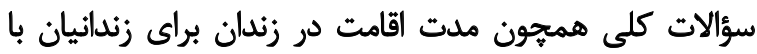

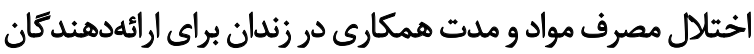

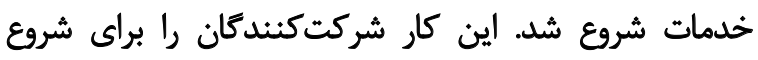

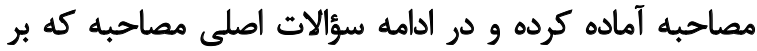

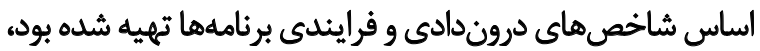

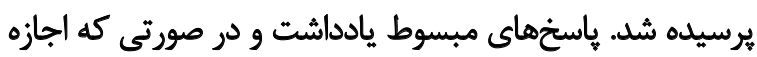

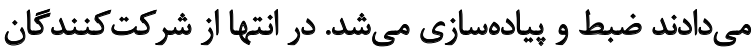

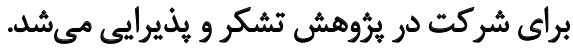

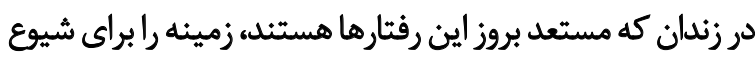

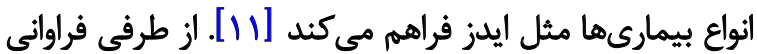

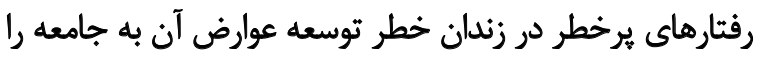

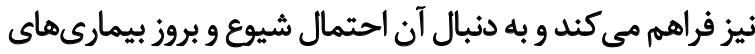

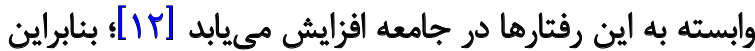

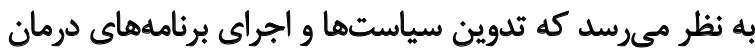

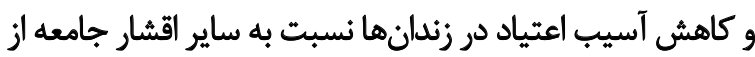

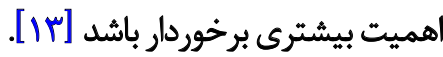
اداره كل بهداشت و درمان سازمان زندانها و اقدامات تأمينى براني

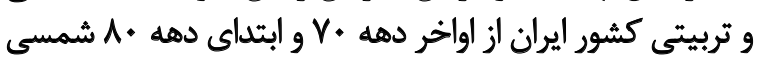

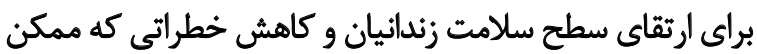

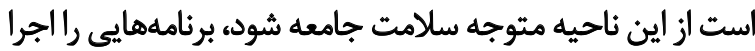

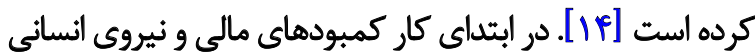

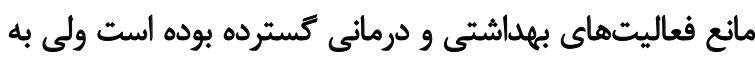

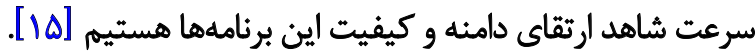

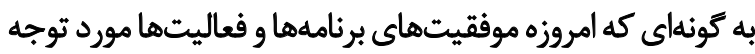

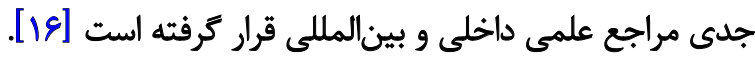

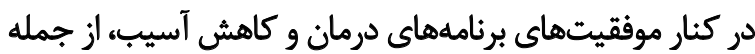

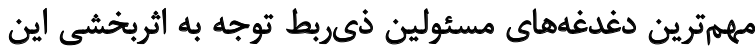

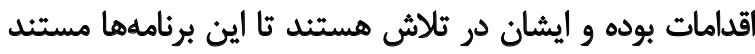

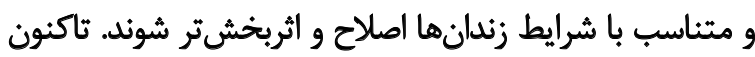

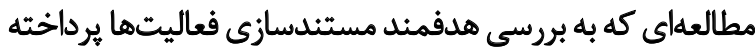

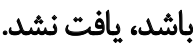

با توجه به مطالب بيانشده، يروهش حاضر با هدف بررسى دئ زئ

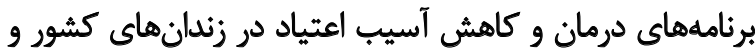

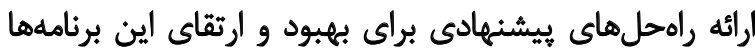

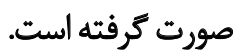
روش

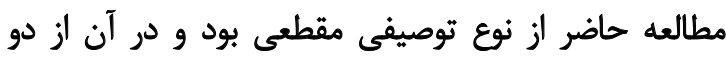

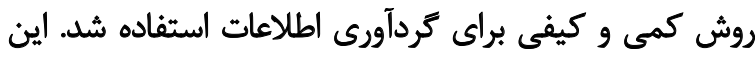

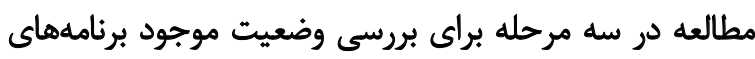

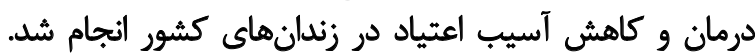

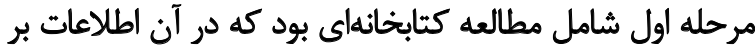

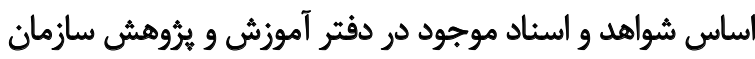

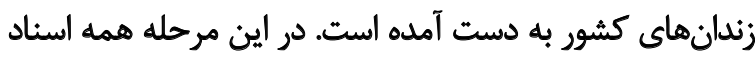

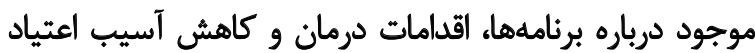

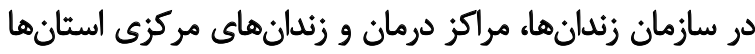

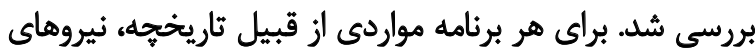

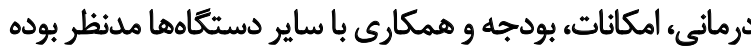

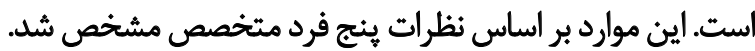
در مرحله دوم شاخصهاى درونداد و فرايند از مطالعات

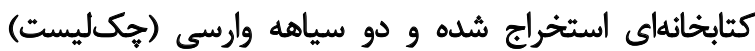


را بيعيرى نمايد. كزارشهاى زندان آب حيات' در زمينه شيوع

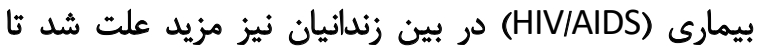

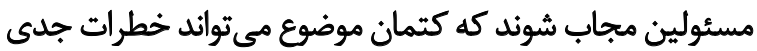

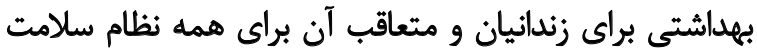

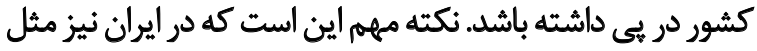

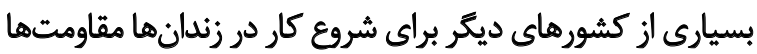

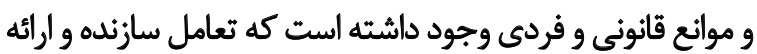

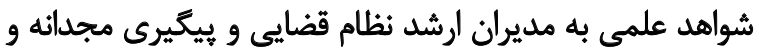

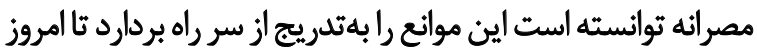

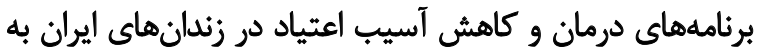
عنوان الكوى موفق قابل ارائه به كشورهاى ديكر باشي آشند

شروع برنامههاي كاهش آسيب با آكاهىرسانى، آموزش از

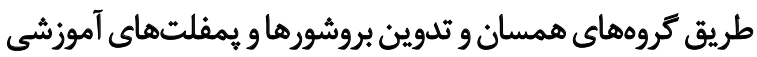

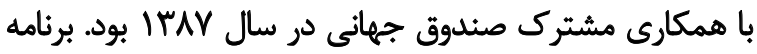

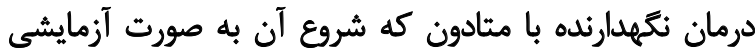

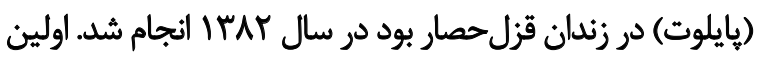

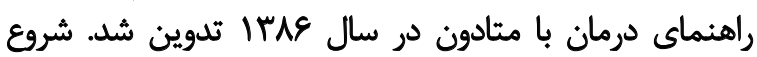

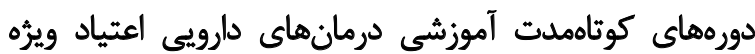

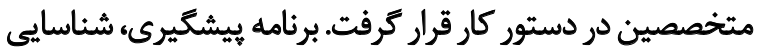

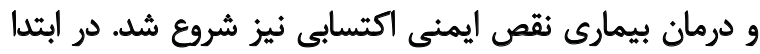

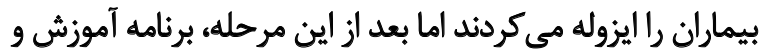

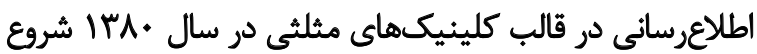

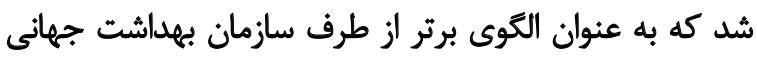

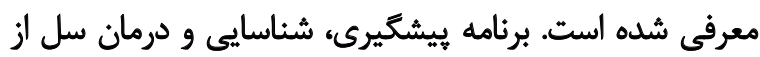

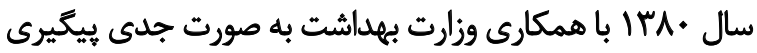

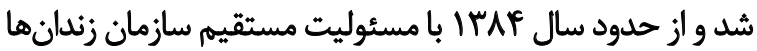

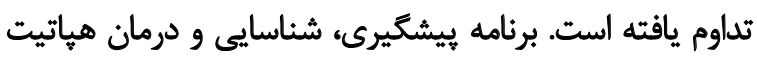

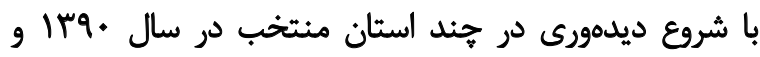

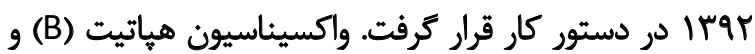

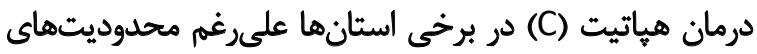

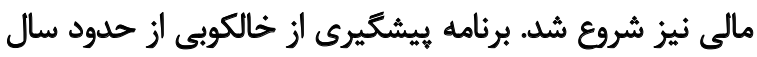

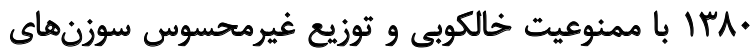

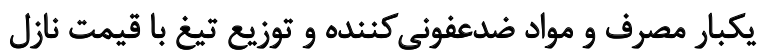

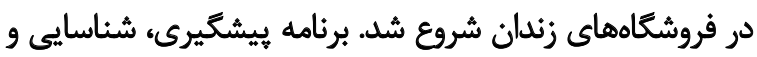

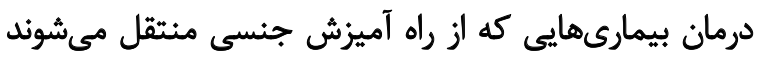

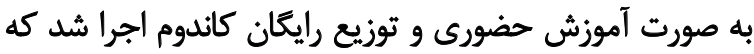
على ترغم وقفه جند ساله به علت بحرى بحث سياست كشورى در در زمينه تنظيم خانواده هنوز ادامه دارد.

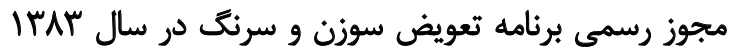

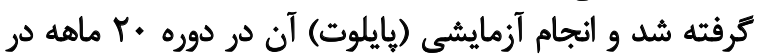

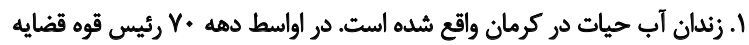

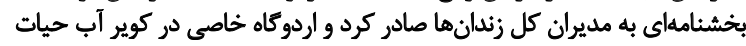

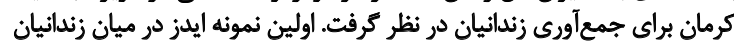

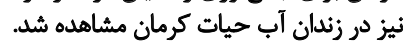

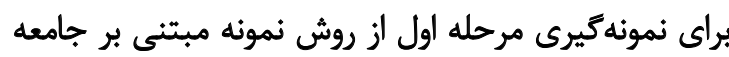

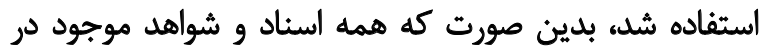

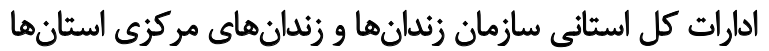

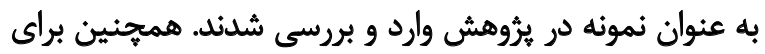

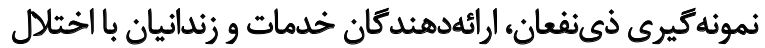

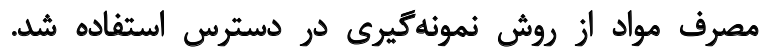

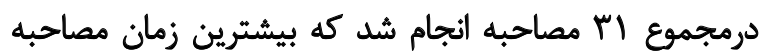
IT.

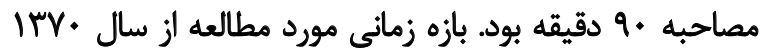

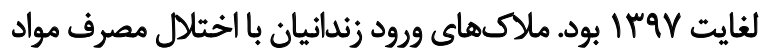

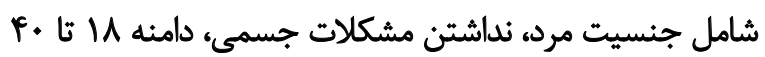

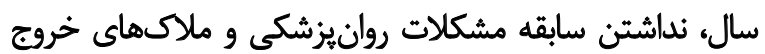

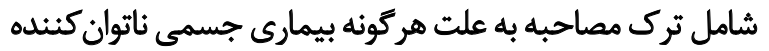

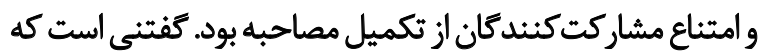
زندانهاى بررسىشده شامل زندانهاى مركزى آب استان بودي در بخش كثابخانهاي تمام مطالعات موجود در كثابخانه دفتر

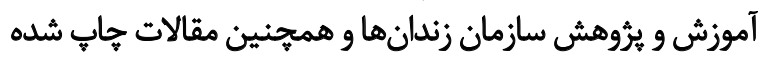

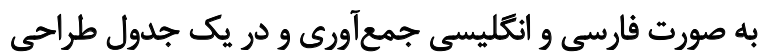

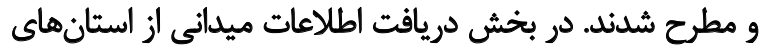

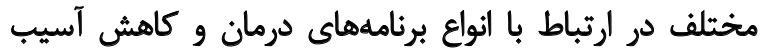

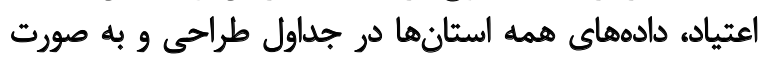

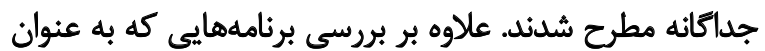

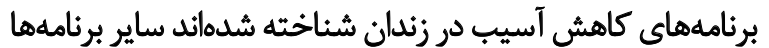

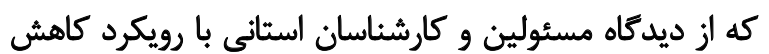

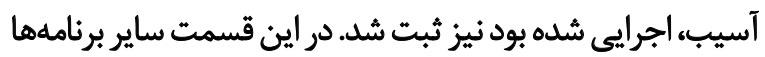

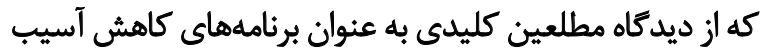

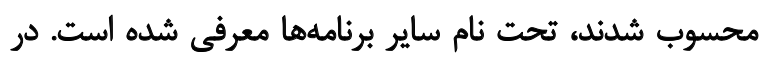

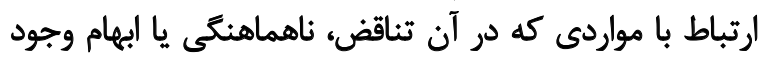
داشته است نيز از روش اجماع استفاده شده است.

يافتهها

تاريخجها برنامههاي كاهش آسيب دو زندانهاي كثور به

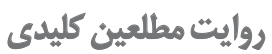

دو برنامه محورى كاهش آسيب و درمان در زندان يويكيرى

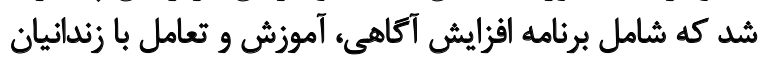

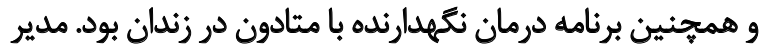

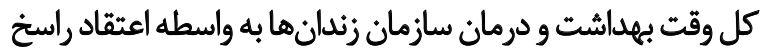

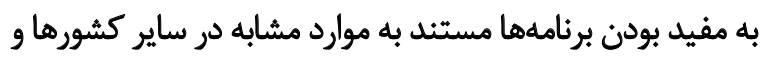

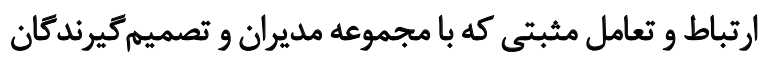

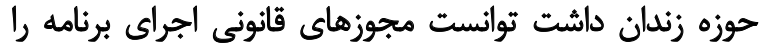
اخذ و از سال •A راهاندازى برنامههاي كاهش آسيب در زندان بران 
هزار نفر تحت درمان نتههدارئده با متادون هستند كه يكى از

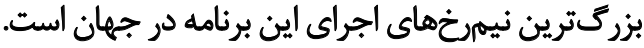
نيمى از استانها شامل اردبيل، اصفهان، ايلام، بوشهر، خراسان

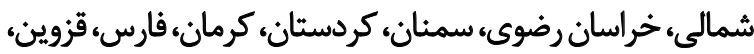

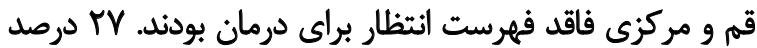

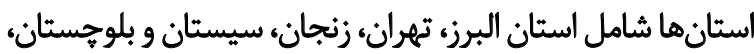

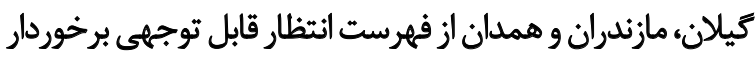

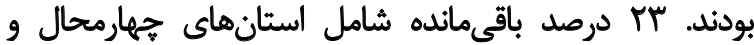

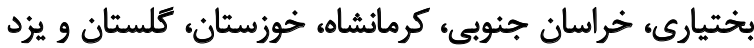

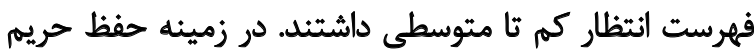

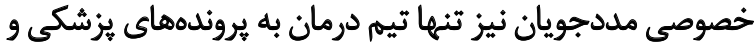

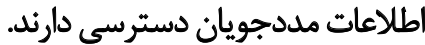
كمبود فضا، نيروى انسانى و اعتبارات در مثايسه با حجم كار در

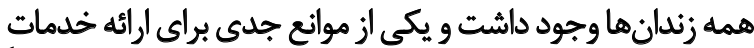

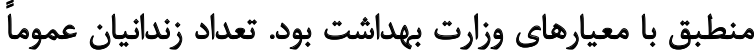

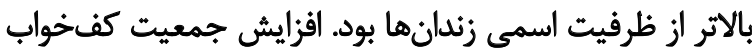

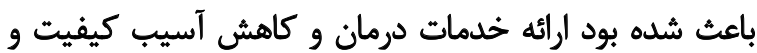

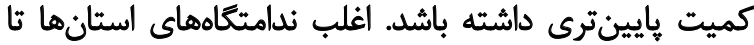

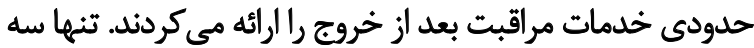

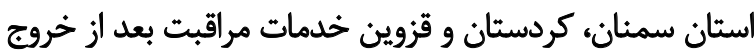

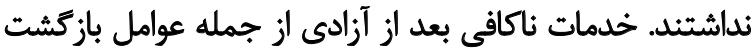

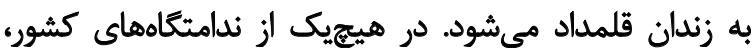

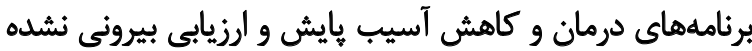

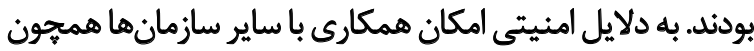

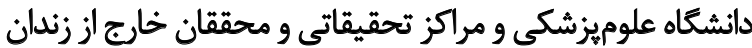

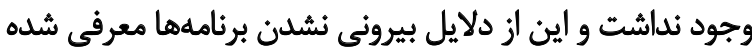

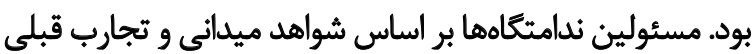

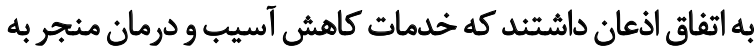

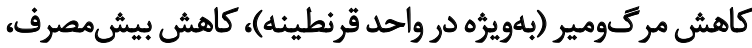

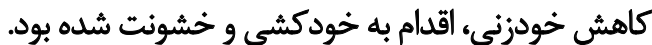

به جز ستاد سازمان و جند استان، شامل استانهاى خراسان

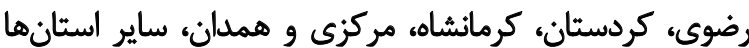

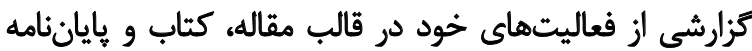

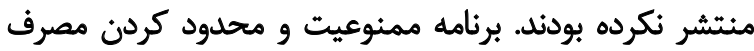

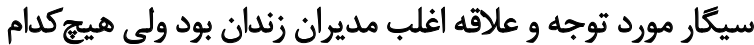

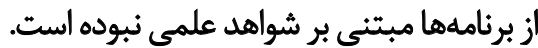

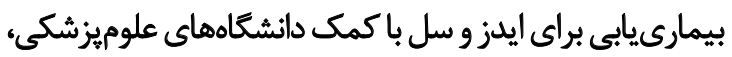

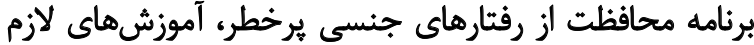

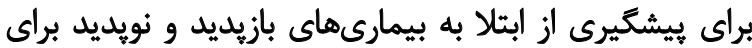

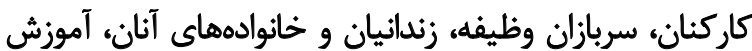

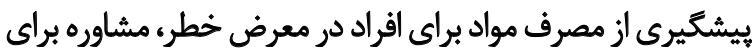

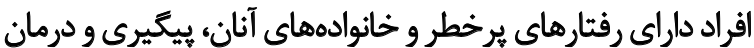

زندانهاي مركزى سه استان اصفهان، همدان و تهران شروع شده

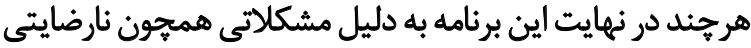

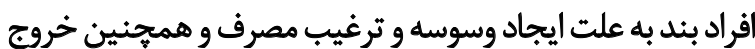

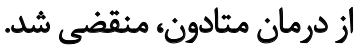

اسناد ملي و يؤوهش هاى قبلى در حوزه درمان و كاهش آسيب أخثتال مصرف مواد

آنجهه از اسناد و تحقيقات به دست آمد، نشان ميدهد كهد كهد ابتدا

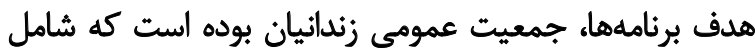

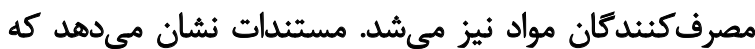

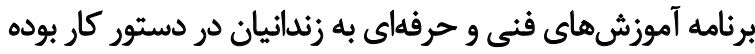

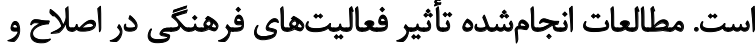

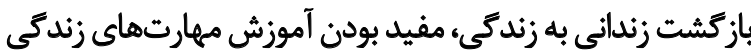

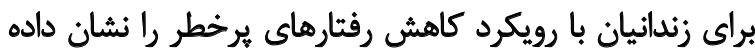

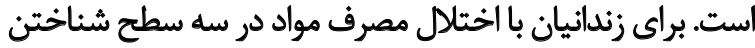
نوع شيوع، بيشگيرى و درمان مطالعاتى انجام كرفته است. از

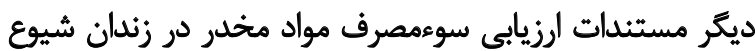

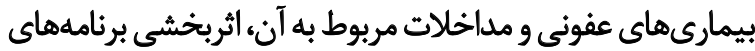

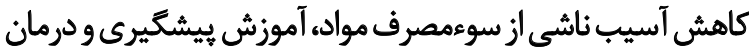

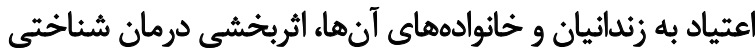

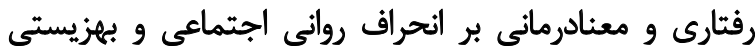

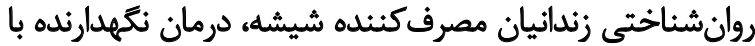

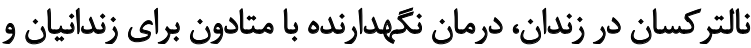

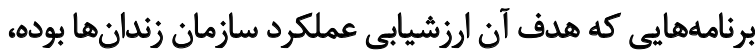

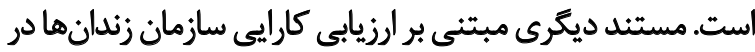

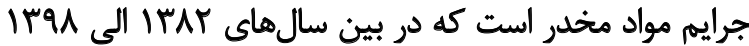

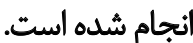

برنامههاى كاهش آسيب و درمان اعثياد در زندانهاى استيان هائ مهثمثلف

يافتهايي كه در بازديد از زندانهاي مراكز استانها به دست ديت

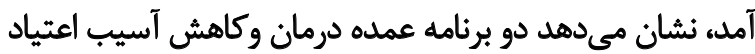

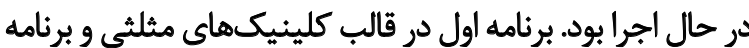

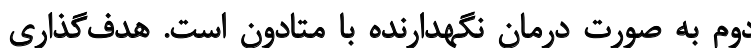

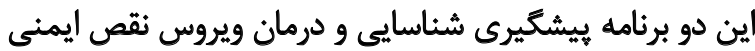

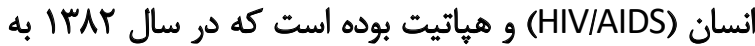
صورت آزمايشى در زندان قزل حصار شروع شده است. در همد

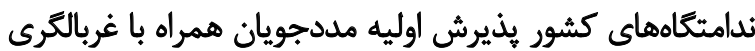

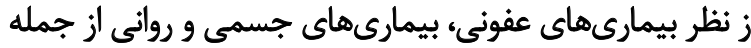

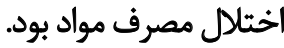

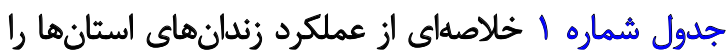

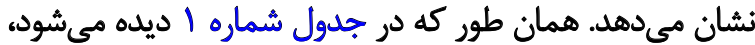

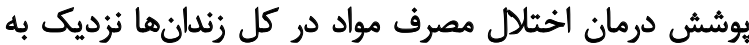

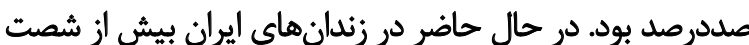


جدول ا. خلاصه عملكرد ندامثكاهها در زميئه برنامههاي اقدامشده يا در دست اقدام حوزه درمان و كاهش آسيب در اختلالات مصرف مواد

\begin{tabular}{|c|c|c|c|c|c|c|c|}
\hline كاهش بأبأسيب أمهاى & 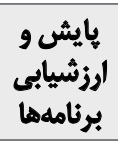 & مراقبت بعد & 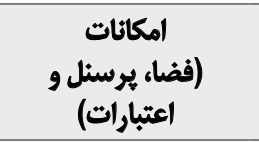 & ميزان يوشاهشا & غربالئي & هماهنكى با هورتكل & استان \\
\hline$\checkmark$ & خير & $\checkmark$ & كمبود يرسنل & فاقد ليست أثتظار & $\checkmark$ & $\checkmark$ & 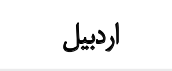 \\
\hline$\checkmark$ & خير & $\checkmark$ & كمبود يهسنل و اعتبارات & فاقد ليست انتظار & $\checkmark$ & $\checkmark$ & اصفهان \\
\hline$\checkmark$ & خير & $\checkmark$ & 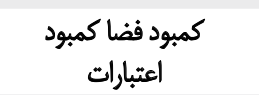 & بالا & $\checkmark$ & $\checkmark$ & البرز البر \\
\hline$\checkmark$ & خير & $\checkmark$ & كمبود فضاو ويرسنل و & فاقد ليست انتظظار & $\checkmark$ & $\checkmark$ & ايلام \\
\hline$\checkmark$ & خير & $\checkmark$ & كمبود اعتبار & 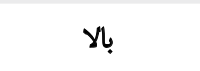 & $\checkmark$ & $\checkmark$ & آذربايجان شرقى \\
\hline$\checkmark$ & حير & $\checkmark$ & كمبود اعتبار و فضا & فاقد ليست أتثظار & $\checkmark$ & $\checkmark$ & أذربايجان غُرِيى \\
\hline$\checkmark$ & خير & $\checkmark$ & كميود هيرسنل و اعتبارات & فاقد ليست أنتظار & $\checkmark$ & $\checkmark$ & بوشهر \\
\hline$\checkmark$ & خير & $\checkmark$ & كمبود اعثبار، نيرو و فضا & siguط & $\checkmark$ & $\checkmark$ & تهران \\
\hline$\checkmark$ & خير & $\checkmark$ & كمبود فضا و يرسنل و & بايين & $\checkmark$ & $\checkmark$ & بخهيارهحال و \\
\hline$\checkmark$ & خير & $\checkmark$ & كمبود اعتبارات و يرسنل & ضعيف & $\checkmark$ & $\checkmark$ & خراسان جنوبى \\
\hline$\checkmark$ & خير & $\checkmark$ & كمبود در هر سه حوزه & فاقد ليست انتظار & $\checkmark$ & $\checkmark$ & خراسان رضوى \\
\hline$\checkmark$ & خير & $\checkmark$ & كمبود فضا و يرسنل & فاقد ليست انتظار & $\checkmark$ & $\checkmark$ & خراسان شمالى \\
\hline$\checkmark$ & خير & $\checkmark$ & كمبود برئل & ليستب انتظظار محلدود & $\checkmark$ & $\checkmark$ & حِوزنستان \\
\hline$\checkmark$ & خير & $\checkmark$ & كمبود فضا و يرسنل & 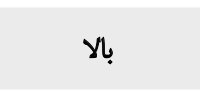 & $\checkmark$ & $\checkmark$ & زنجان \\
\hline$\checkmark$ & خير & 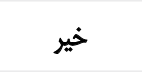 & كمبوددر هر سه حوزه & قاقد ليست انتظظار & $\checkmark$ & $\checkmark$ & سمنان \\
\hline$\checkmark$ & خير & $\checkmark$ & كمبود يرسنل و اعتبارات & بالا & $\checkmark$ & $\checkmark$ & بلوجيستان و \\
\hline$\checkmark$ & خير & $\checkmark$ & كمبود يرسنل & فاقد ليست انتظار & $\checkmark$ & $\checkmark$ & فارس \\
\hline$\checkmark$ & خير & 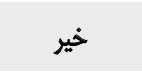 & كمبود در هر سه حوزه & فاقد ليست انتظار & $\checkmark$ & - & قزوين \\
\hline$\checkmark$ & خير & $\checkmark$ & كمبود اعتبار & فاقد ليست انتظار & $\checkmark$ & $\checkmark$ & قم \\
\hline$\checkmark$ & خير & خير & كمبود اعتبارات & قاقد ليست انتظار & $\checkmark$ & $\checkmark$ & كردستان \\
\hline$\checkmark$ & خير & $\checkmark$ & كمبود اعتبار & قاقد اليسيت انتظظار & $\checkmark$ & $\checkmark$ & كرمان \\
\hline$\checkmark$ & خير & $\checkmark$ & كمبود اعتبارات و يرسنل & متروطيط & $\checkmark$ & $\checkmark$ & كرمانشاه \\
\hline اطلاعات ناقص & خير & $\checkmark$ & اطلاعات ناقص & |طلاعات ناقص & $\checkmark$ & $\checkmark$ & كبويلويه و بويراحمد \\
\hline$\checkmark$ & خير & $\checkmark$ & فضبود زياد يبرسنل و و فتبارات & بايين & $\checkmark$ & $\checkmark$ & كلستان \\
\hline$\checkmark$ & خير & $\checkmark$ & كمبود فضا و يرسئل و & بالا & $\checkmark$ & $\checkmark$ & كيلن \\
\hline$\checkmark$ & خير & $\checkmark$ & كمبود اعتبار و فضا & فاقد ليست أنتظار & $\checkmark$ & $\checkmark$ & ل ل لرستان \\
\hline$\checkmark$ & خير & $\checkmark$ & كمبود يرسنل و اعتبارات & بالا & $\checkmark$ & $\checkmark$ & مازئدران \\
\hline$\checkmark$ & خير & $\checkmark$ & كمبود يرسنل & فاقد ليست انتظار & $\checkmark$ & $\checkmark$ & 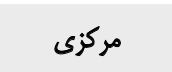 \\
\hline
\end{tabular}




\begin{tabular}{|c|c|c|c|c|c|c|c|}
\hline تداوم برثامههاي & 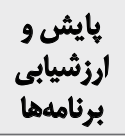 & از خراقبت بعد & 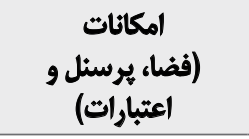 & ميزان يوششا برشا & غريالمرى اوليه & هماهنئكى با & استان \\
\hline$\checkmark$ & خير & $\checkmark$ & كمبود اعثبار & فاقد ليست انتظار & $\checkmark$ & $\checkmark$ & هرمزكان \\
\hline$\checkmark$ & $\checkmark$ & $\checkmark$ & مناسب & بالا & $\checkmark$ & $\checkmark$ & همدان \\
\hline$\checkmark$ & خير & $\checkmark$ & كمبود فضا، نيرو و اعثبار & بالا & $\checkmark$ & $\checkmark$ & يزد \\
\hline
\end{tabular}

جدول r. نسبت تيم درمان به مددجويان در زندان

\begin{tabular}{|c|c|c|c|}
\hline (به ازاى هر دويست نفر يك تيم درمان & تعداد تيم درمان فعال & 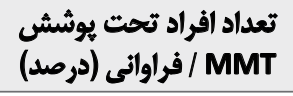 & استان \\
\hline امكان شناسايع وجود ندارد & بنج بزشك، جهار برستار، يك كارشناس & $\Delta 1 \Delta(r q / F)$ & 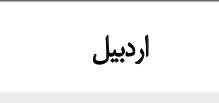 \\
\hline امكان شناسايع وجود ندارد & دو تيم درمان & اطلاعات ناقص & اروميه \\
\hline r بتيم درمان & يك تيم درمان & $v \Delta \cdot(r \cdot)$ & اصفهان \\
\hline يك تيهم درمان & ي ئيج تيم درمان قران دوارديى & $\| f \cdot \cdot(r g / f)$ & البرز البر \\
\hline يك تيم درمان & يك تيم درمان & $r q \Delta\left(F \Delta t t^{*}+\right)$ & إيلام \\
\hline يك تيم درمان & يك تيم درمان قراردادي & $r \Delta \cdot(r V / \Lambda)$ & بوشهر \\
\hline تيمه درمان متثاسب است & 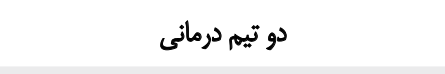 & $\varphi \cdot(1 \cdot)$ & تبريز \\
\hline امكان شناسايع وجود ندارد & اطلاعات ناقص & اطلاعات ناقص & تهران \\
\hline كمبود يزشك ثابت & 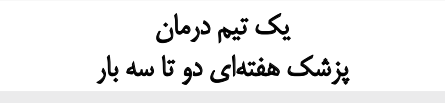 & YNA (YA) & تجهارمحال و بختيارى \\
\hline 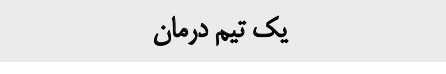 & يك تيم درمان بدون يرستار & $r \Delta \cdot(T \cdot / \Delta)$ & 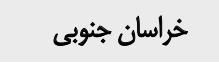 \\
\hline 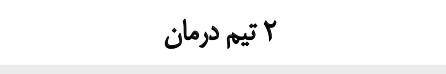 & جهار تيم درمان قراردادى & $M+*(T / / M)$ & خراسان رضوى \\
\hline تيمه درمان متتاسب است & 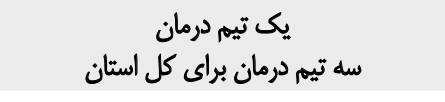 & $r \Delta \cdot(-)$ & خراسان شمالى \\
\hline يك تيهم درمان & جيهار تيم درمان & $\cdots(r)$ & 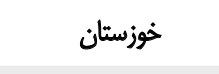 \\
\hline مو تييم درمان & يك تيم درمان قراردادى & $\left.8 \cdot .(\pi)^{2}\right)$ & زنجان \\
\hline تيم درمان مثناسب است & يك تيم درمان قراردادى & $M(T \Delta)$ & سمثان \\
\hline 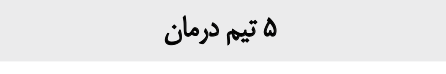 & يك تيهم درمان & $M+.(M r)$ & سيستان و بلوجستان \\
\hline 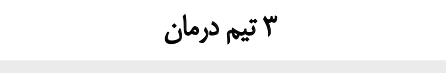 & جهار تيم درمان قراردادى & $P T Q / /(T V / E)$ & فارس \\
\hline يك تيهم درمان & دو تيم درمان قراردادى & $e q(I V / \varphi)$ & 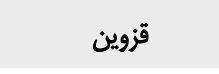 \\
\hline يك تيهم درمان & يك تيم درمان دولتى & $\operatorname{rva}(-)$ & قمى \\
\hline ب بيزشك و يك روانشناس & 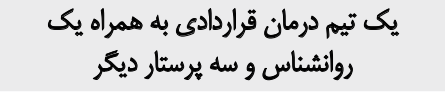 & $g \cdot \cdot \forall \Delta \Delta \cdot(N N)$ & 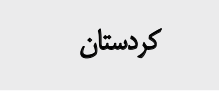 \\
\hline كا ت تيم درمان & 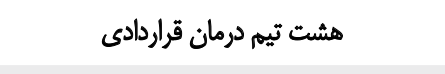 & $\operatorname{PIAY}(T T / F)$ & كرمان \\
\hline 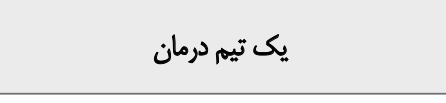 & يك تيه درمان به همراه يك روانشناس و سه & ar) $(-)$ & كرمانشاه \\
\hline
\end{tabular}




\begin{tabular}{|c|c|c|c|}
\hline (به ازاى هر دويست نفر يكى تيبم درمان) & تعداد تيم درمان فعال & تعداد افراد تحت هوشش / فرانى (درصد) & السئان \\
\hline امكان شناسايع وجود ندارد & اطلاعات ناقص & اطلاعات ناقص & كهكيلويه و بويراحمد \\
\hline امكان شناسايي آن وجود ندارد & لزوم يوشش •+.r نفر و كمبود نيرو & $\mid r+\infty\left(r_{*}\right)$ & كلمتان \\
\hline تيم درمان هتناسب است & 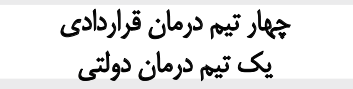 & $1 \cdots(\pi)$ & كيلان \\
\hline امكان شناسايیى وجود ندارد & دو تيم درمان & اطلاعات ناقص & ل ل لرستان \\
\hline تيم درمان متناسب است & هشت تيم درمان & $I r \cdots(I V / r)$ & مازندران \\
\hline دو تيمى درمان & جهار تيم درمان قراردادي و دولتى & 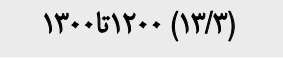 & مركزى \\
\hline امكان شناسايي وجود ندارد & سه تيه درمان & اطلاعات ناقص & 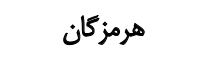 \\
\hline امكان شناسايي وجود ندارد & اطلاعات ناقص & $I r \Delta \cdot(r \cdot)$ & هalin \\
\hline امكان شناسايى وجود ندارد & اطلاعات ناقص & $(m) 1 \cdot 1 \cdot(t) \cdot \Delta$. & 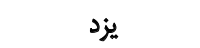 \\
\hline
\end{tabular}

و همجنين كاهش جشمكير موارد جديد شناسايى شيده در

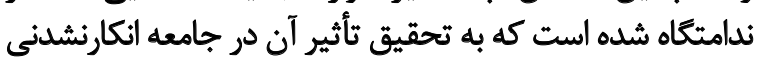

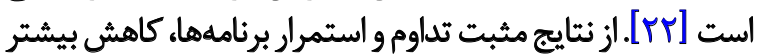

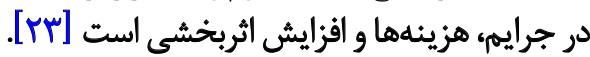

با اينكه خدمات ارائهشده ثا حدود زيادى مبتنى بر يروتكل كشورى است كه از طرف وزارت بهداشت، درمان و آموزش ارئش

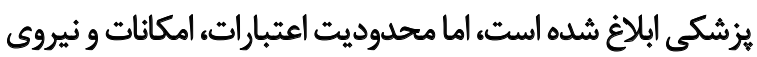

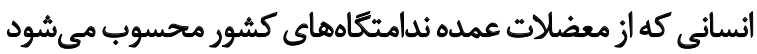

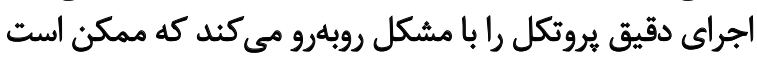

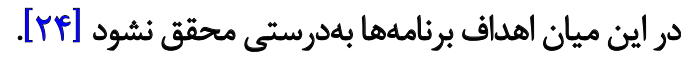
با وجود يوشش نزديك به صددرصدى كه يكى از بزركترين

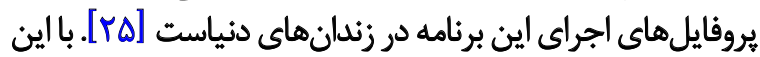

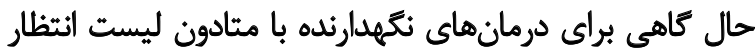

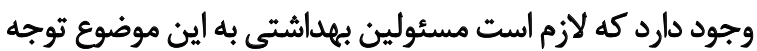
لازم داشته باشئد.

فضاى فيزيكى، تجهيزات ونيروى انسانى نيز متناسب با فزايش

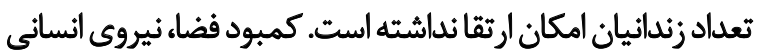

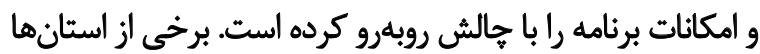

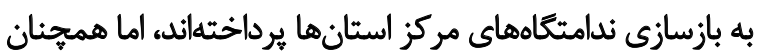

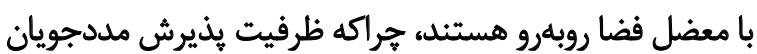

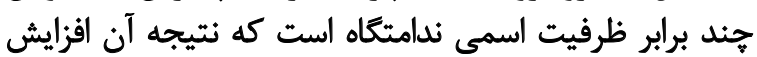

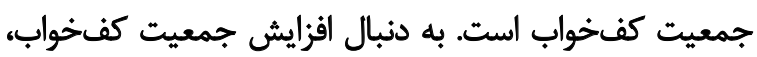

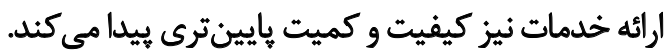
تقويت مراقبتهاى يس از خروج از زندان خصوصاً درباره زنان

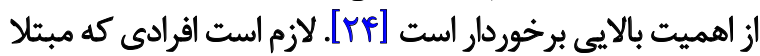

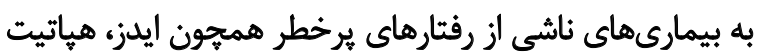

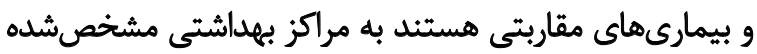

زندانيان يس از آزادى از طريق هماهنكى با دانشعاه علوميزشكى و يا سازمان بهزيستى از مهمثرين فعاليتها در راست راستاى كاهش

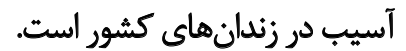

كمبود نيروى انسائي در بخش درمان نئمهارئده با مثادون در

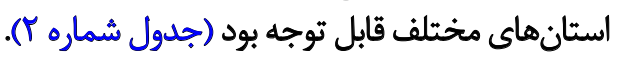
همانطور كله در جدول شماره Y ديده مي شود، تيمهاي

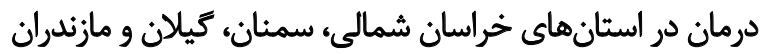

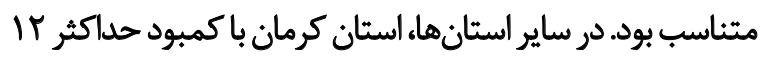

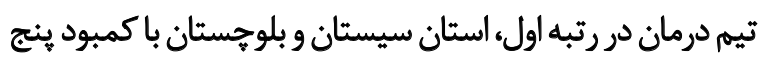

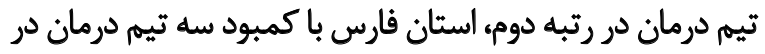

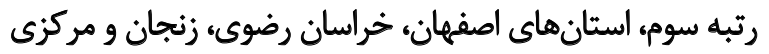

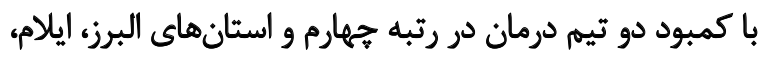

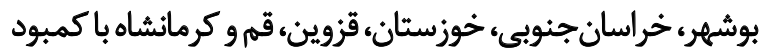

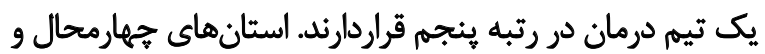

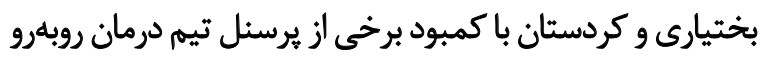

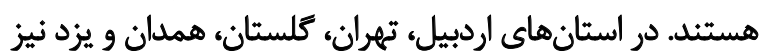

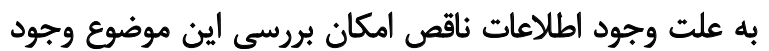
نداشُث. به. ب اجراى مستمر برئامهها به ويرٔه درمان نتخهدارنده با متادون به

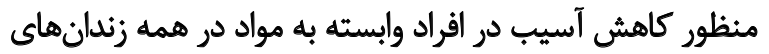

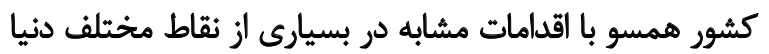

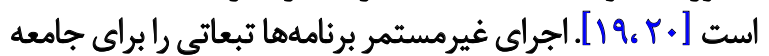

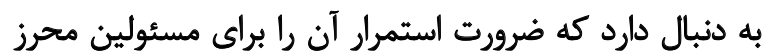

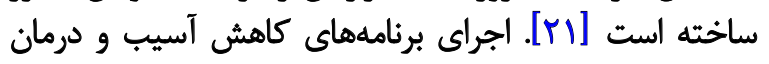

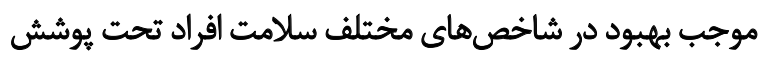




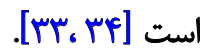

ضمن وجود برخى محدوديتهاي رايج روششناختى كه

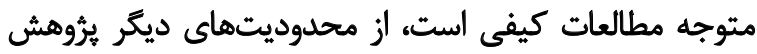

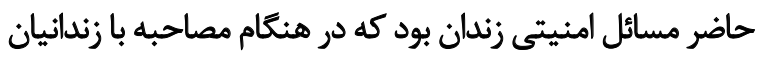

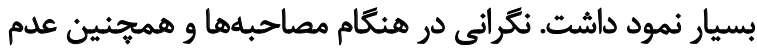

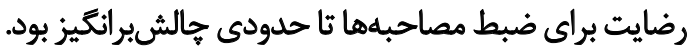

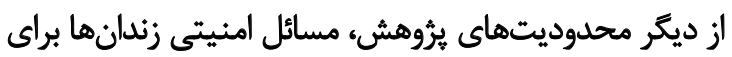

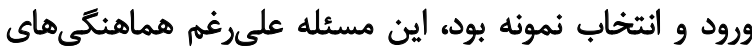

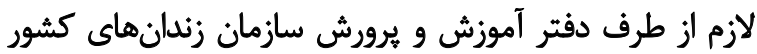

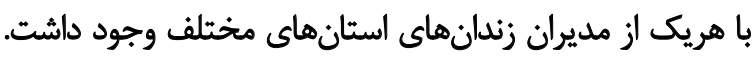

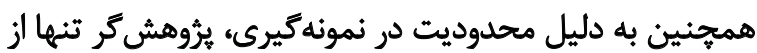

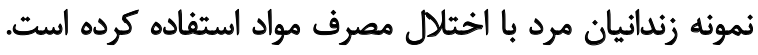

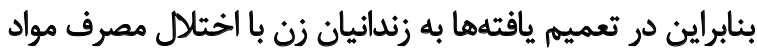

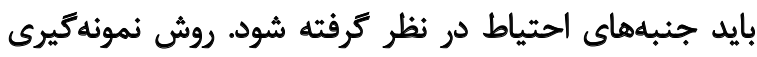

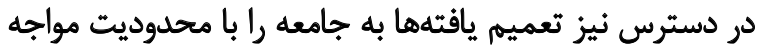

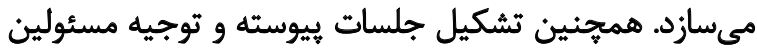

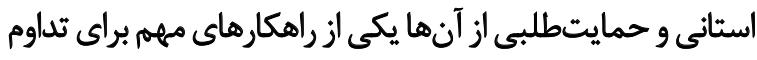

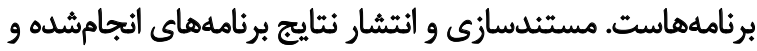

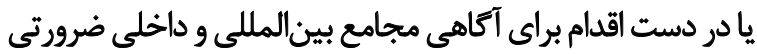

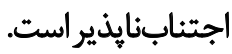

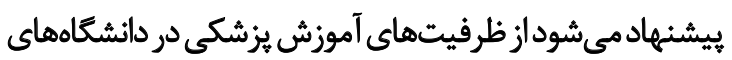

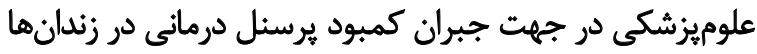

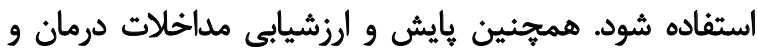

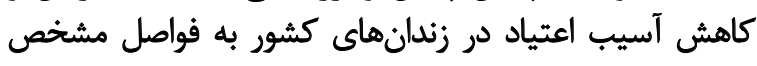

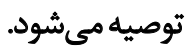

\section{ماحظات اخلاقي - ماتي}

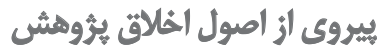

مصاحبهها با هماهنكى قبلى و معرفى كتبى كه از طريق دفتر

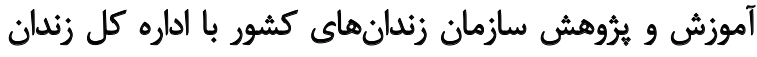

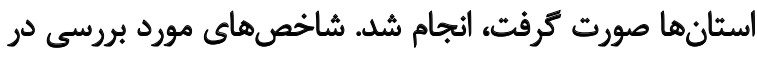

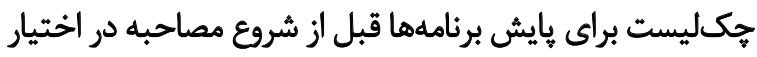

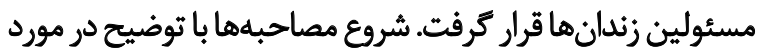

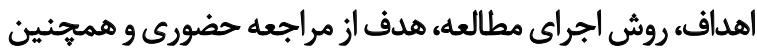

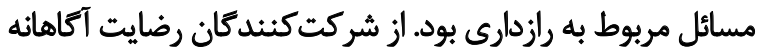

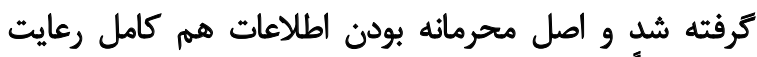

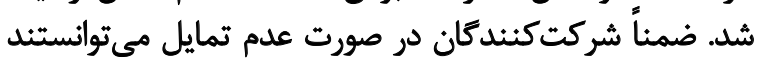

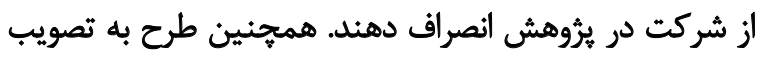

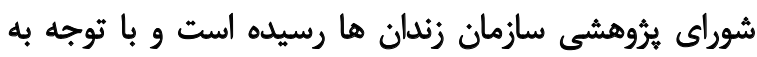

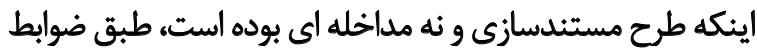
سازمان زندان ها نياز به كد اخلاق نداشته است.

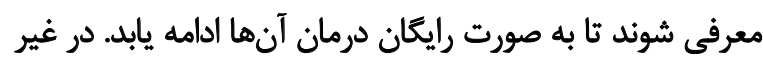

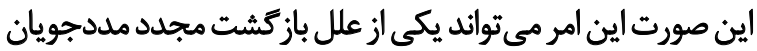

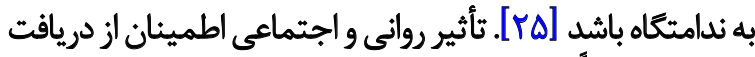

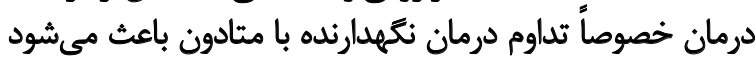

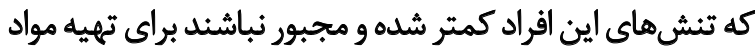

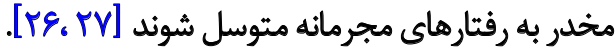

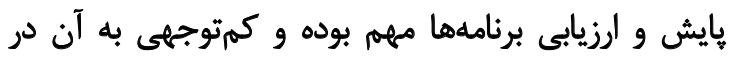

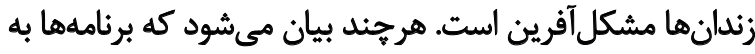

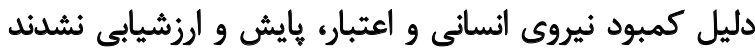

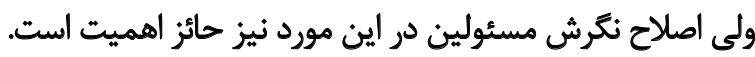

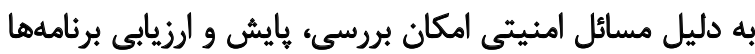

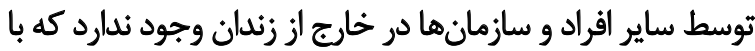

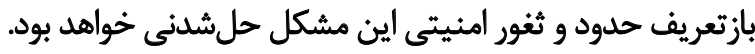

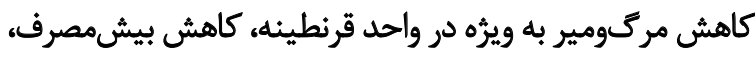

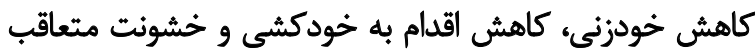

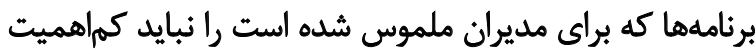

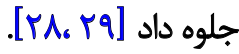

$$
\text { نتيجه بكيرى }
$$

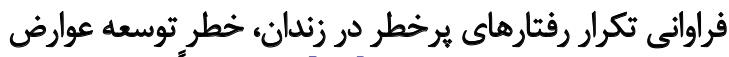

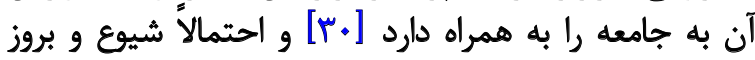

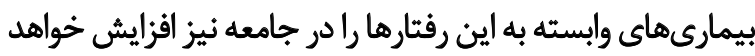

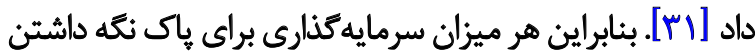

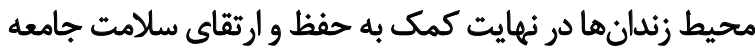

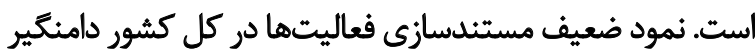

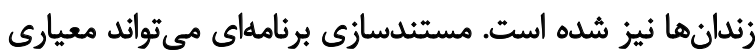

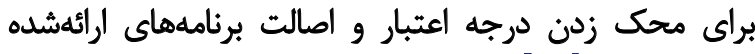

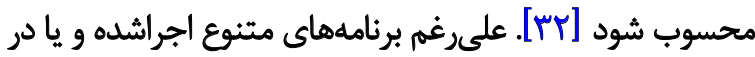

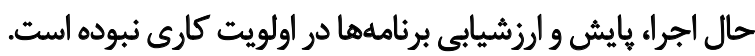

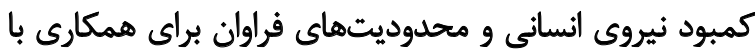

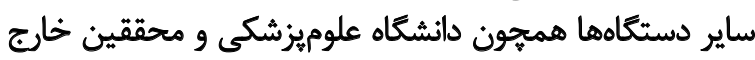

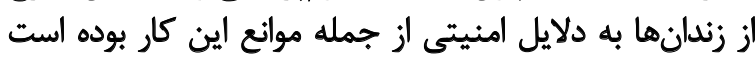

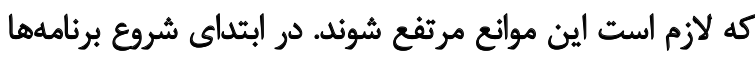

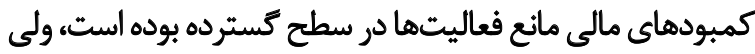

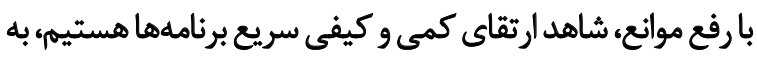

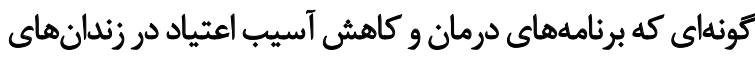

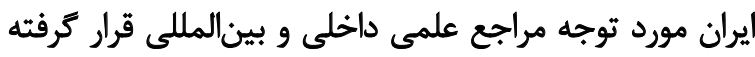

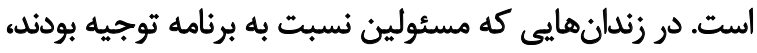

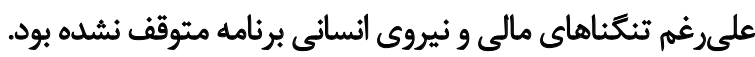

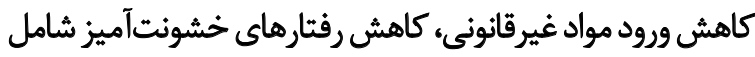

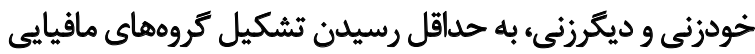

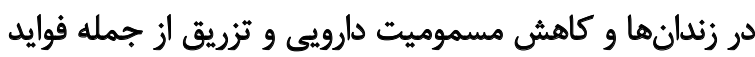

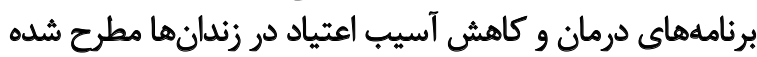




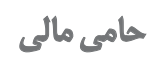

مطالعه حاضر را دفتر آموزش و يُروهش سازمان زندانهاي كشور حمايت مالى كرده است.

$$
\text { مشاركت نويسند مكان }
$$

جمع آورى دادهها: محمدباقر صابرى زفرقندى، رضا آرزومندان،

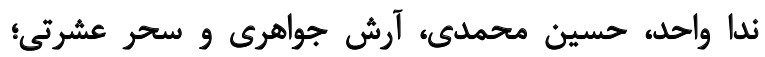

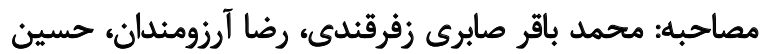

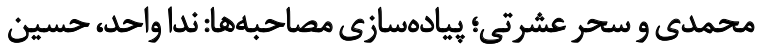

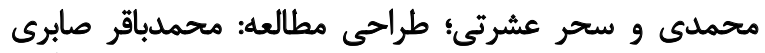

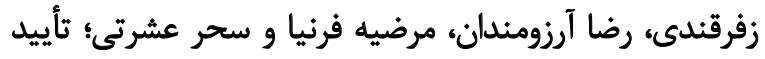
نهايي مقاله: همه نويسندكان.

$$
\text { تعارض منافع }
$$

سفارشدهنده اين مطالعه سازمان زندانهاست و به داليل

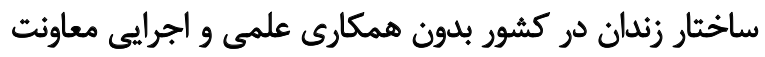

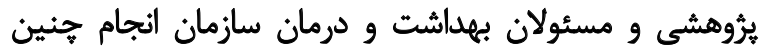

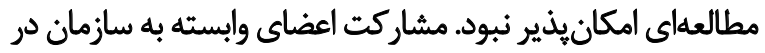

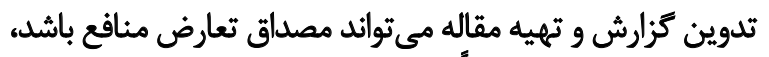

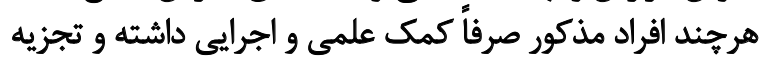

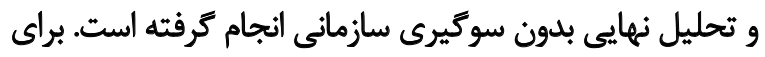

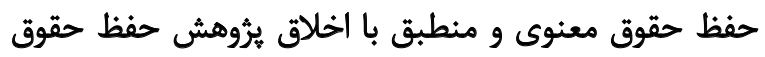

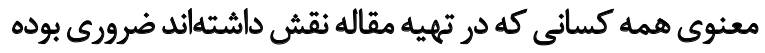

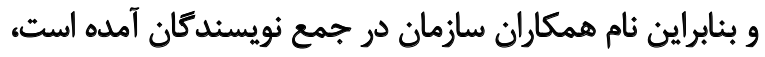

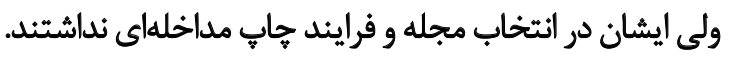

$$
\text { تشكر و قمدردانى }
$$

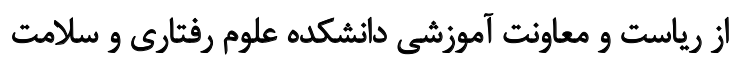

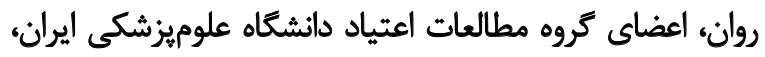

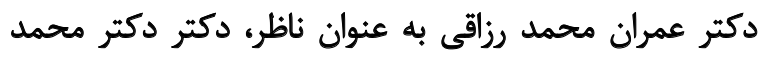

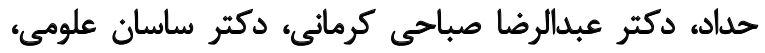

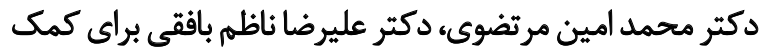

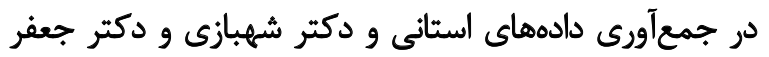

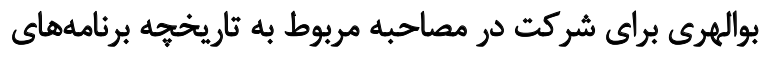

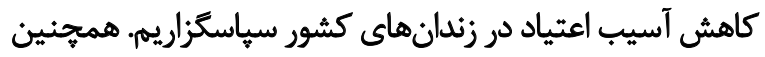

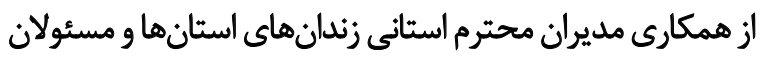

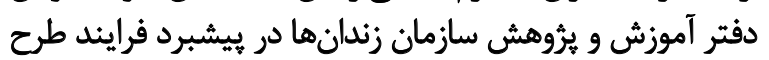

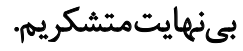




\section{References}

[1] Nunn A, Zaller N, Dickman S, Trimbur C, Nijhawan A, Rich JD. Methadone and buprenorphine prescribing and referral practices in US prison systems: Results from a nationwide survey. Drug and Alcohol Dependence. 2009; 105(1-2):83-8. [DOI:10.1016/j. drugalcdep.2009.06.015] [PMID] [PMCID]

[2] Blaauw E, Roesch R, Kerkhof A. Mental disorders in European prison systems: Arrangements for mentally disordered prisoners in the prison systems of 13 European countries. International Journal of Law and Psychiatry. 2000; 23(5-6):649-63. [DOI:10.1016/ S0160-2527(00)00050-9]

[3] Zamani S, Farnia M, Tavakoli S, Gholizadeh M, Nazari M, Seddighi AA, et al. A qualitative inquiry into methadone maintenance treatment for opioid-dependent prisoners in Tehran, Iran. International Journal of Drug Policy. 2010; 21(3):167-72. [DOI:10.1016/j.drugpo.2009.03.001] [PMID]

[4] Huby RH. Life in prison: Perspectives of drug injectors. Deviant Behavior. 2000; 21(5):451-79. [DOI:10.1080/01639620050085843]

[5] Eshrati B, Asl RT, Dell CA, Afshar P, Millson PM, Kamali M, et al. Preventing HIV transmission among Iranian prisoners: initial support for providing education on the benefits of harm reduction practices. Harm Reduction Journal. 2008; 5(1):21. [DOI:10.1186/1477-7517-5-21] [PMID] [PMCID]

[6] Zamani S, Kihara M, Gouya MM, Vazirian M, Ono-Kihara M, Razzaghi EM, et al. Prevalence of and factors associated with HIV-1 infection among drug users visiting treatment centers in Tehran, Iran. Aids. 2005; 19(7):709-16. [DOI:10.1097/01. aids.0000166094.24069.72] [PMID]

[7] Organization WH. Multi-city study on drug injecting and risk of HIV infection: A report prepared on behalf of the WHO International Collaborative Group. Geneva: World Health Organization; 1994. https://apps.who.int/iris/bitstream/handle/10665/62037/WHO_PSA_94.4.pdf?sequence=1

[8] Beyrer C, Jittiwutikarn J, Teokul W, Razak MH, Suriyanon V, Srirak N, et al. Drug use, increasing incarceration rates, and prison-associated HIV risks in Thailand. AIDS and Behavior. 2003; 7(2):153-61. [DOI:10.1023/a:1023946324822]

[9] Dolan K, Rutter S, Wodak AD. Prison-based syringe exchange programmes: A review of international research and development. Addiction. 2003; 98(2):153-8. [DOI:10.1046/j.13600443.2003.00309.x] [PMID]

[10] Horton A. Heroin users: The need for improved treatment for incarcerated women. Social Work in Public Health. 2011; 26(2):176-88. [DOI:10.1080/19371910903182773] [PMID]

[11] Jacob J, Stöver H. The transfer of harm-reduction strategies into prisons: needle exchange programmes in two German prisons. International Journal of Drug Policy. 2000; 11(5):325-35. [DOI:10.1016/S0955-3959(00)00050-5]

[12] Koulierakis G, Gnardellis C, Agrafiotis D, Power KG. HIV risk behaviour correlates among injecting drug users in Greek prisons. Addiction. 2000; 95(8):1207-16. [DOI:10.1046/j.13600443.2000.95812077.x] [PMID]

[13] Onorato IM, McCray E, Branch FS. Prevalence of human immunodeficiency virus infection among patients attending tuberculosis clinics in the United States. Journal of Infectious Diseases. 1992; 165(1):87-92. [DOI:10.1093/infdis/165.1.87] [PMID]
[14] Roshanfekr P, Farnia M, Dejman M. The effectiveness of harm reduction programs in seven prisons of Iran. Iranian Journal of Public Health. 2013; 42(12):1430. [PMID]

[15] Pourahmad M, Javady A, Karimi I, Ataei B, Kassaeian N. Seroprevalence of and risk factors associated with hepatitis $B$, hepatitis $\mathrm{C}$, and human immunodeficiency virus among prisoners in Iran. Infectious Diseases in Clinical Practice. 2007; 15(6):368-72. [DOI:10.1097/IPC.0b013e318142ce16]

[16] Zafarghandi MBS, Jadidi M, Khalili N. Iran's activities on prevention, treatment and harm reduction of drug abuse. International Journal of High Risk Behaviors \& Addiction. 2015; 4(4):e59737. [DOI:10.5812/ijhrba.22863] [PMID] [PMCID]

[17] United Nations Office on Drugs and Crime. Evaluation of substance use treatment programs [Interbet]. 2015 [Updated 2015]. Available from: https://www.unodc.org/documents/islamicrepublicofiran/publications/1jan2015/Evaluation_of_Substance_Use_Treatment_Programmes-EN.pdf

[18] World Health Organization. Work book 4: process evaluation [Internet]. 2000 [Updated 2000]. Available from: https://apps. who.int/iris/bitstream/handle/10665/66584/WHO_MSD_ MSB_00.2e.pdf;jsessionid=097876A1DA8895D0405B0A22E4D9F $5 \mathrm{C} 4$ ? sequence $=5$

[19] Bayan Zadeh AS, Bolhari J, Atef Vahid MK, Nouri Ghasem Abadi R, Fatali Lavasani F, Karimi Kismi E. [The role of medication and psychological interventions in harm reduction of substance use in addicted prisoners (Persian)]. Iranian Journal of Psychiatry and Clinical Psychology. 2007; 14(55):47-38. http:/ / rims.iums. ac.ir/article-1-731-fa.pdf

[20] Farnia M, Ebrahimi B, Shams A, Zamani S. Scaling up methadone maintenance treatment for opioid-dependent prisoners in Iran. International Journal of Drug Policy. 2010; 21(5):422-4. [DOI:10.1016/j.drugpo.2010.03.008] [PMID]

[21] Werb D, Wood E, Small W, Strathdee S, Li K, Montaner J, et al. Effects of police confiscation of illicit drugs and syringes among injection drug users in Vancouver. International Journal of Drug Policy. 2008; 19(4):332-8. [DOI:10.1016/j.drugpo.2007.08.004 [PMID] [PMCID]

[22] Shahbazi M, Farnia M, Rahmani K, Moradi G. Trend of HIV/ AIDS prevalence and related interventions administered in prisons of Iran-13 years' experience. Iranian Journal of Public Health. 2014; 43(4):471-9. [PMID] [PMCID]

[23] Oliver P, Keen J, Rowse G, Ewins E, Griffiths L, Mathers N. The effect of time spent in treatment and dropout status on rates of convictions, cautions and imprisonment over 5 years in a primary care-led methadone maintenance service. Addiction. 2010 105(4):732-9. [DOI:10.1111/j.1360-0443.2009.02856.x] [PMID]

[24] Grella CE, Rodriguez L. Motivation for treatment among women offenders in prison-based treatment and longitudinal outcomes among those who participate in community aftercare. Journal of Psychoactive Drugs. 2011; 43(sup1):58-67. [DOI:10.1080 /02791072.2011.602275

[25] Farnia M, Shahbazi M, Moradi G, Alizadeh S, Ebrahi B, Kalle M. [Evaluation of harm reduction programs in prisons from the attitude and viewpoint of Iranian prison staff (Persian)]. Journal of School of Public Health \& Institute of Public Health Research 2013; 11(1):29-44. http://sjsph.tums.ac.ir/article-1-5016-fa.html

[26] Nunes EV, Sullivan MA, Levin FR. Treatment of depression in patients with opiate dependence. Biological Psychiatry. 2004; 56(10):793-802. [DOI:10.1016/j.biopsych.2004.06.037] [PMID] 
[27] Acosta MC, Marsch LA, Xie H, Guarino H, Aponte-Melendez Y. A web-based behavior therapy program influences the association between cognitive functioning and retention and abstinence in clients receiving methadone maintenance treatment. Journal of Dual Diagnosis. 2012; 8(4):283-93. [DOI:10.1080/15504263.2012.72 3317] [PMID] [PMCID]

[28] Moradi AR, Emdadi A, Soori B, Mostafavi E. Prevalence of human immunodeficiency virus infection among injection drug users released from Jail. Addiction \& Health. 2012; 4(3-4):151. [PMCID] [PMID]

[29] Ross M. Health and health promotion in prisons. Milton Park: Routledge; 2012. [DOI:10.4324/9780203083239]

[30] Hutton HE, Treisman GJ, Hunt WR, Fishman M, Kendig N, Swetz A, et al. HIV risk behaviors and their relationship to posttraumatic stress disorder among women prisoners. Psychiatric Services. 2001; 52(4):508-13. [DOI:10.1176/appi.ps.52.4.508] [PMID]

[31] Grinstead OA, Zack B, Faigeles B, Grossman N, Blea L. Reducing postrelease HIV risk among male prison inmates: A peer-led intervention. Criminal Justice and Behavior. 1999; 26(4):453-65. [DOI:10.1177\%2F0093854899026004003]

[32] Kamarulzam an A, Reid SE, Schwitters A, Wiessing L, El-Bassel N, Dolan K, et al. Prevention of transmission of HIV, hepatitis B virus, hepatitis $C$ virus, and tuberculosis in prisoners. The Lancet. 2016; 388(10049):1115-26. [DOI:10.1016/S0140-6736(16)30769-3]

[33] Gough E, Kempf MC, Graham L, Manzanero M, Hook EW, Bartolucci A, et al. HIV and hepatitis B and C incidence rates in US correctional populations and high risk groups: A systematic review and meta-analysis. BMC Public Health. 2010; 10(1):777. [DOI:10.1186/1471-2458-10-777] [PMID] [PMCID]

[34] Zafarghandi MB, Eshrati S, Vameghi M, Ranjbar H, Arezoomandan R, Clausen T, et al. Drug-related community issues and the required interventions in open drug scenes in Tehran, Iran: a qualitative study protocol. BMJ Open. 2019; 9(10):e030488. [DOI:10.1136/bmjopen-2019-030488] [PMID] [PMCID] 